\title{
GROIN FLAP: A GOOD CONVERGE FOR HAND INJURY
}

\author{
MD. SHAMSUZZAMAN ${ }^{1}$, SK. BORHAN UDDIN ${ }^{2}$, MD. MASOOM $^{3}$, MD. ANOWARUL ISLAM $^{4}$, \\ AZIZUL HAQUE 5
}

\begin{abstract}
Summary:
Fifty cases of hand trauma of different aetiology with soft tissue loss with exposed tendons and bones were treated in NITOR and DMCH, Dhaka between January '97 and December '02 with groin flap. Eighty three percent (83\%) cases have good results with excellent flap adhesion and no flap loss. Seventeen percent (17\%) cases have some degree of flap loss which were taken to be acceptable. Overall result in terms of restoring the hand function was encouraging which was approximately eighty eight percent (88\%).
\end{abstract}

\section{Introduction:}

Hand is the most important organ of our body, which consists of well formed skeletal framework on which multiple tendons work to bring out the purposeful function. This skeletal system and tendons are covered with soft tissues and skin. Most of the hand trauma are caused by machinery injuries, road traffic accidents, electric burns etc in our country. As a result the skin and underlying soft tissues are grossly damaged, so that the bones and tendons are exposed. When these bones and tendons were exposed for a long time, it becomes dried, desiccated, infected and ultimately destroyed with residual loss of function. This can easily be prevented by covering the exposed bone and tendon with a groin flap.

The method of providing skin cover following hand trauma require an awareness of the pathological features of the common injury pattern. ${ }^{1}$ Pain hand injuries are of three main types - cutting and slicing, crushing degloving and avulsion. Cutting and slicing injury can be closed directly after sufficient excision of the devitalized skin edges. Crush injury may range from subungual haematoma to crushing of fingers with or without bony damage. Even after meticulous surgical excision of non-viable tissue, the bed is poorer recipient site for skin graft, so flap cover is the choice to close the wound. Degloving and avulsion injuries usually confined to the skin and subcutaneous tissue, so tendons and bones are usually exposed which should primarily covered with a flap.

The provision of skin cover $^{2}$ in hand trauma takes priority because the granulation tissue which is produced in the process of healing by secondary intention matures to fibrous tissue and the presence of raw surface is a potential focus of infection. Firbrosis and infection are both harmful which are responsible for stiffness of the joints following hand trauma. Adequate skin cover with a flap immediately eliminates the infection and largely ceases the production of granulation tissues.

As hand performs a unique mechanical function, it is imperative to provide a good soft tissue coverage for the hand ${ }^{3}$ Skin grafts when used it causes wound contraction and limits the 'gliding of the tendons directly under skin graft Moreover, skin graft fail to provide sensibility which is important for hand function Flap cover is often necessary for all above reasons. All flaps include the entire thickness of skin and subcutaneous tissue and carry with them their own blood supply. They provide better and more durable skin cover. They provide sensibility because of their own cutaneous nerve supply and also provide subcutaneous fat through which tendons can glide.

The surgeons when replace the 'missing tissue' lie should always keep in mind the quality of the tissue

1. Associate Professor, Ortho-Surgery, Dhaka Medical College, Dhaka

2. Consultant Ortho-Surgery, Central Police Hospital, Rajarbag, Dhaka

3. Registrar, Ortho-Surgery, Dhaka Medical College Hospital

4. Resident, Ortho-Surgery, Dhaka Medical College Hospital

5. Resident, Ortho-Surgery, Dhaka Medical College Hospital 
that is lost and attempt to replace the tissue with similar in kind ${ }^{4}$.

Groin flap is an important flap for coverage of the exposed tendons and bones of the hand. It is an axial pattern flap with a minimum tissue bulk and good skin colour and texture. It provides good amount of length and breadth, which is usually sufficient for resurfacing of the dorsal or palmar aspect of the hand. The hand can be placed in a comfortable position without making discomfort to the shoulder, elbow and wrist joint. The major disadvantage of this flap are it requires two stage surgery as other pedicle flap and the pedicle of the flap is close to the external genetalia which is at potential risk of having infection.

The present study is carried out on fifty groin flaps which are used for resurfacing of the hand.

\section{Materials and methods:}

Fifty cases of hand defects were treated with groin flap in the plastic surgery unit of National Institute of Traumatology and Orthopaedic, Rehabilitation (NITOR) and DMCH, Dhaka between January '97 to December '02

Groin flap 5 is a medially based flap which provide a large, area of soft tissue coverage for the hand defects. The vascular basis of the flap is superficial circumflex iliac artery (SCIA) that arise from the femoral artery approximately $2.5 \mathrm{~cm}$ below the mid point of the inguinal ligament.

The superficial circumflex iliac artery traverses laterally within the subcutaneous fat, parallel and inferior to the inguinal ligament. At the medial border of the sartorius muscle. The flap is raised from lateral to medial from the anterior superior iliac spine in the subcutaneous plane. When the lateral border of the sartorius muscle is encountered, the fascia over the sartorius and medial tissues were, taken with the flap. This flap was approximately $19 \times 10 \mathrm{~cm}$ in dimension primary closure is usually be accomplished and the ultimate scar is essentially a straight line in the groin crease.

The age of the patients ranged from 15 years to 55 years with a mean age of 32.27 years. All the patients were male.

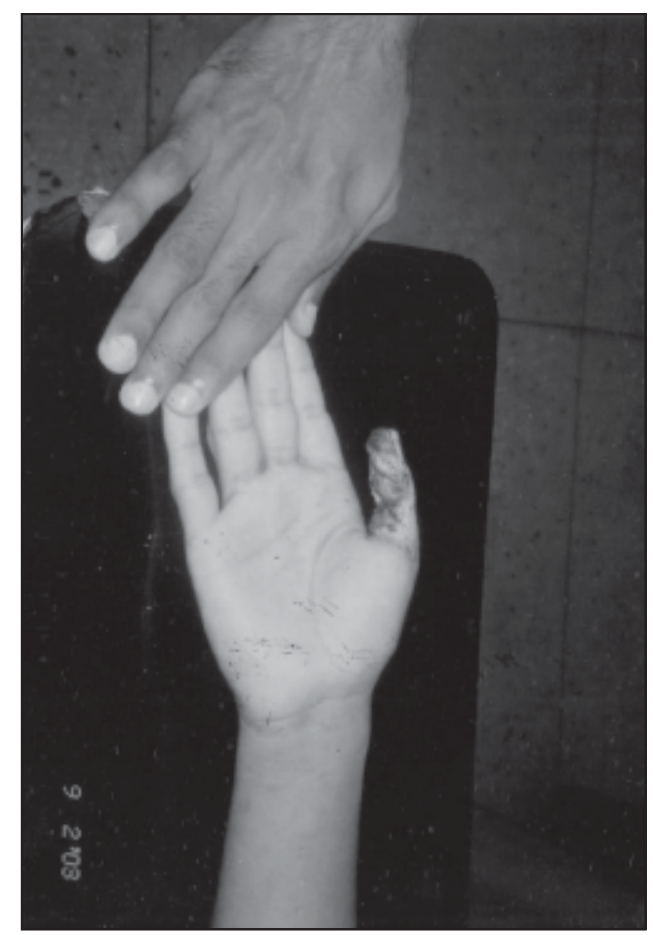

Fig. 1: Electric burn of Rt. thumb

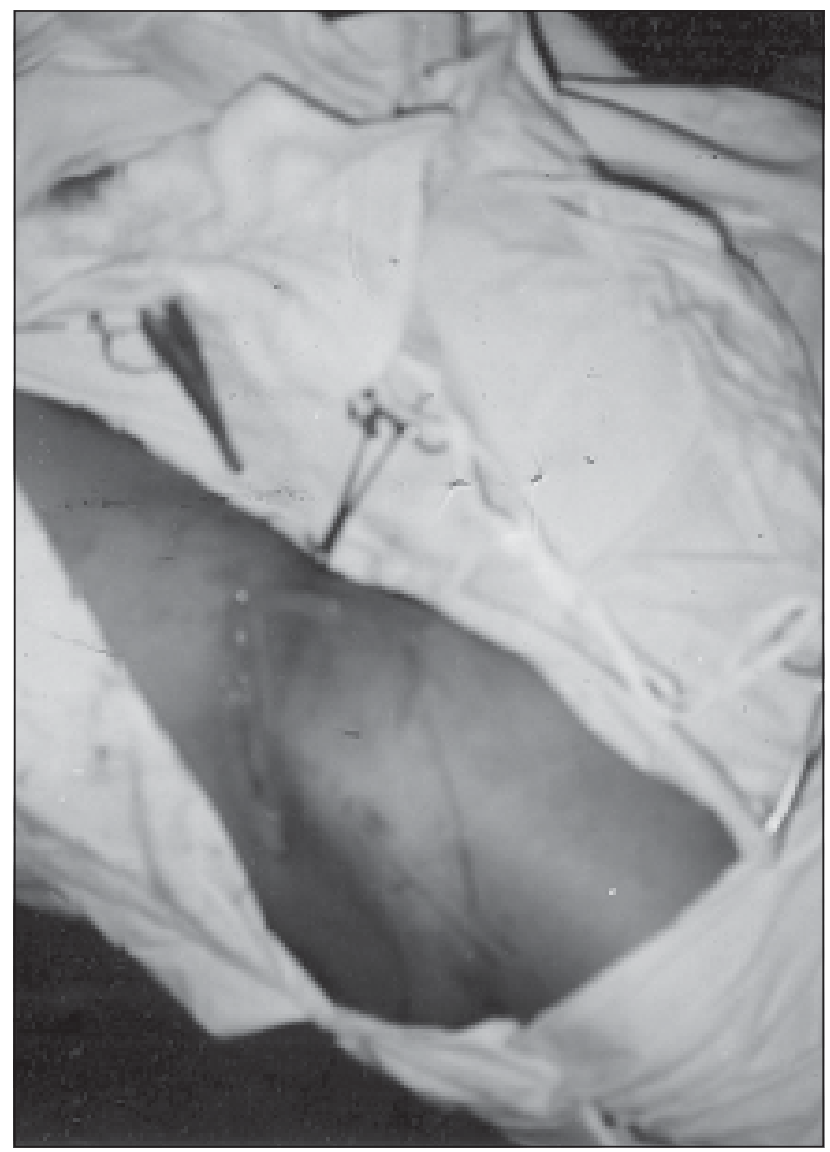

Fig. 2: Growin flap designed 


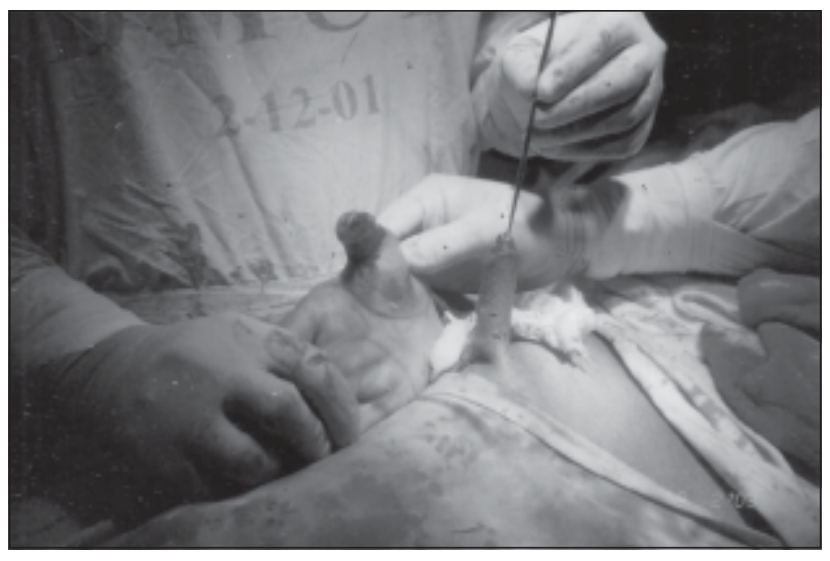

Fig. 3: Growin flap raised

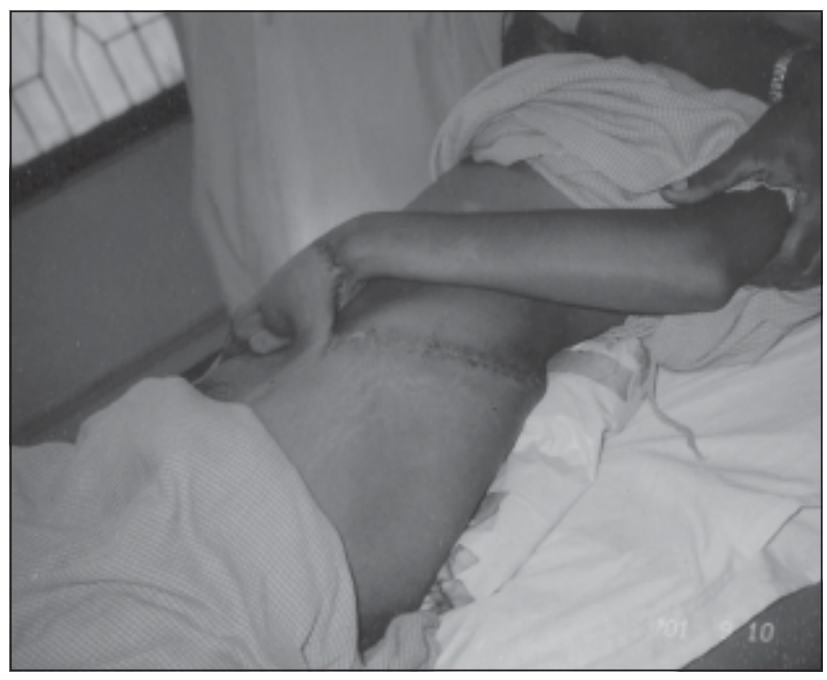

Fig. 5: Flap coverage of dorsum of hand

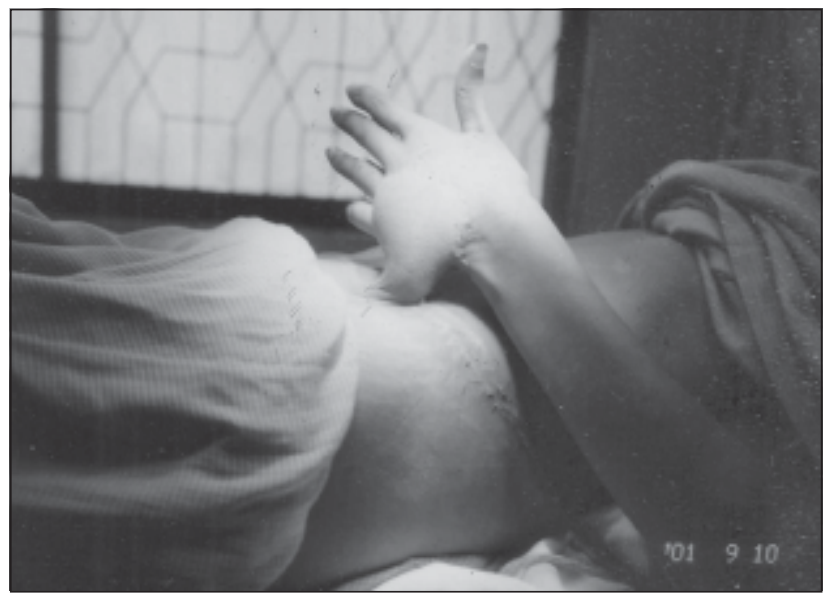

Fig. 7: Flap coverage of dorsum of hand

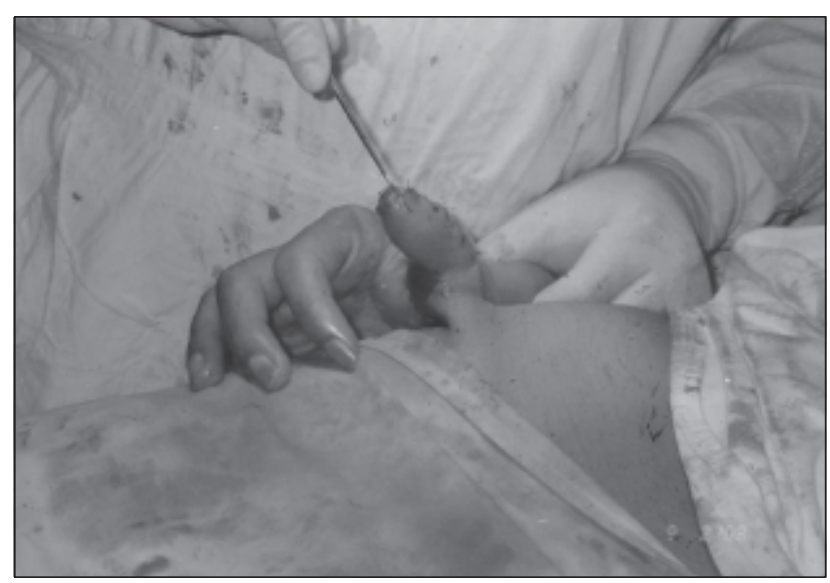

Fig. 4: Wound coverage

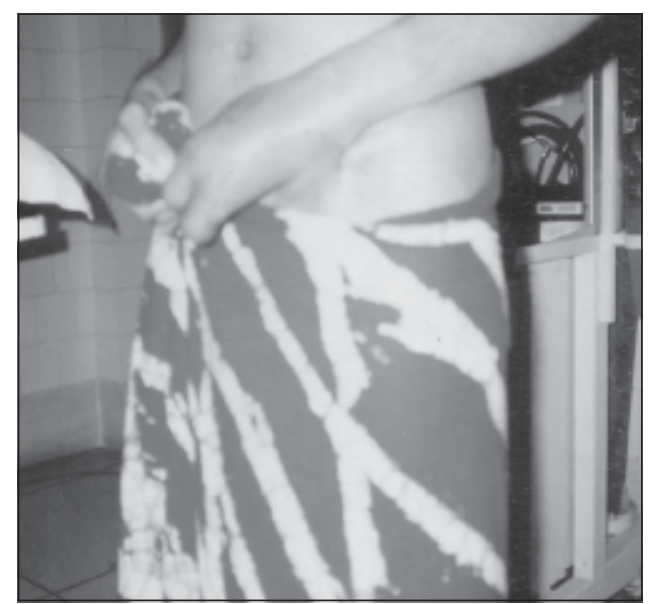

Fig. 6: Flap coverage of dorsum \& volar aspect of hand

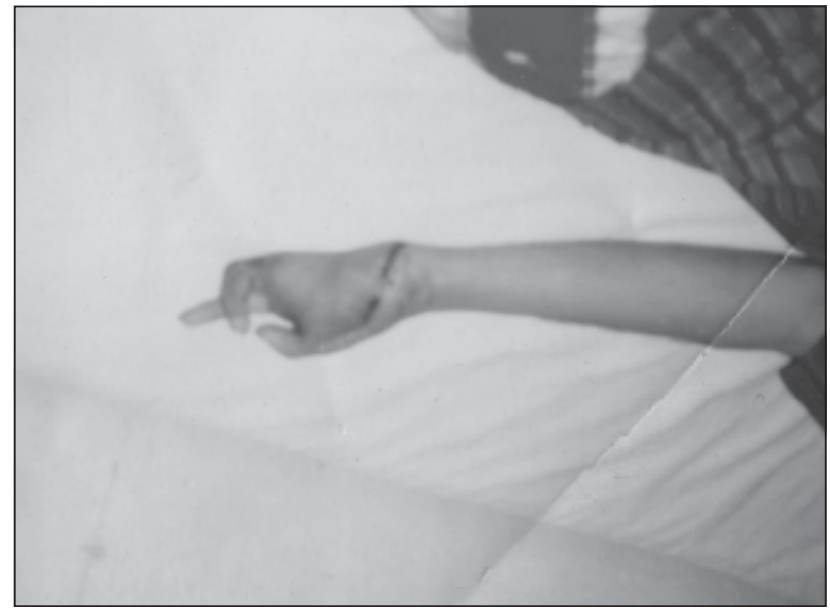

Fig. 8: Flap coverage for hand injury following bomb blast. 
Of the 50 patients, $30(60 \%)$ have their hand defects due to machinery injury, $10(20 \%)$ cases were due to road traffic accidents and the rest of $10(20 \%)$ cases were due to electric burn (Table-I).

Table-I

Aetiology of the hand defects requiring flap cover and the number of cases.

\begin{tabular}{lc}
\hline Aetiology & Number of cases $(\mathrm{n}=50)$ \\
\hline Road traffic accident & $10(20 \%)$ \\
Machinery accident & $30(60 \%)$ \\
Electric burn & $10(20 \%)$ \\
\hline
\end{tabular}

The sites of the hand defects varies, of the 50 patients, 30(60\%) patients have their defects on the dorsum o the hand, 14(28\%) patients have defects on the palmar aspect of the hand and the rest 06(12\%) patients have defects on the first web space (TableII).

Table-II

Site of wound requiring flap cover and the number of cases

\begin{tabular}{lc}
\hline Site of wound & Number of cases $(\mathrm{n}=50)$ \\
\hline Dorsum of the hand & $30(60 \%)$ \\
Palm of the hand & $14(28 \%)$ \\
First web space & $06(12 \%)$ \\
\hline
\end{tabular}

All the flaps hand minimum length of $10 \mathrm{~cm}$, ten $(20 \%)$ of them hand length between $10 \mathrm{~cm}$ and $15 \mathrm{~cm}$, thirty (60\%) between $15 \mathrm{~cm}$ and $17 \mathrm{~cm}$ and ten (20\%) flaps had length between $17 \mathrm{~cm}$ and $20 \mathrm{~cm}$ (Table-III).

Table-III

Length of the flap and the number of cases

\begin{tabular}{lc}
\hline Length of the flap & Number of cases $(\mathrm{n}=50)$ \\
\hline $10 \mathrm{~cm}$ to $15 \mathrm{~cm}$ & $10(20 \%)$ \\
$15 \mathrm{~cm}$ to $17 \mathrm{~cm}$ & $30(60 \%)$ \\
$17 \mathrm{~cm}$ to $20 \mathrm{~cm}$ & $10(20 \%)$ \\
\hline
\end{tabular}

The minimum width of the flap was $05 \mathrm{~cm}$. Fifteen (30\%) flaps had a width between $5 \mathrm{~cm}$ to $7 \mathrm{~cm}$ and thirty five (70\%) flaps between $7 \mathrm{~cm}$ to $10 \mathrm{~cm}$ (Table-IV).
Table-IV

\begin{tabular}{lc}
\hline Width of the flap & Number of cases $(\mathrm{n}=50)$ \\
\hline $5 \mathrm{~cm}$ to $7 \mathrm{~cm}$ & $15(30 \%)$ \\
$7 \mathrm{~cm}$ to $10 \mathrm{~cm}$ & $35(70 \%)$ \\
\hline
\end{tabular}

Width of the flap and the number of cases.

Complications were measured in the terms of flap loss. Underlying haematoma and mild to moderate infections were sproradic and of little significance. Florid infection invariably produce flap loss through flap congestion and vascular compromise. Forty cases (80\%) had no flap loss. Ten (20\%) patients had partial flap loss at the apex which were salvageable after excision of necrotic area and advancement of the flap and resuturing it to the wound margin (Table-V).

\section{Table-V}

\begin{tabular}{|c|c|}
\hline Complications & $\begin{array}{l}\text { hber of cases } \\
(\mathrm{n}=50)\end{array}$ \\
\hline No flaps loss & $40(80 \%)$ \\
\hline Marginal distal flap loss & $08(16 \%)$ \\
\hline Distal flap loss up to $5 \%$ of flap length & $02(04 \%)$ \\
\hline Distal flap loss $>5 \%$ of flap length & Nil \\
\hline \multicolumn{2}{|l|}{ Complications in terms of flap loss. } \\
\hline \multicolumn{2}{|c|}{$\begin{array}{l}\text { Results: } \\
\text { Forty ( } 80 \%) \text { case had good results with satisfactory } \\
\text { flap adhesion and no flap loss. Ten ( } 20 \%) \text { cases with } \\
\text { apical flap necrosis were taken to be acceptable. } \\
\text { There was no cases in this series where alternate } \\
\text { modes of reconstruction was required (Table-VI). }\end{array}$} \\
\hline
\end{tabular}

Table-VI

\begin{tabular}{llc}
\hline Result & Criteria & $\begin{array}{c}\text { No. of cases } \\
(\mathrm{n}=50)\end{array}$ \\
\hline Good & $\begin{array}{l}\text { No flap loss Satisfactory } \\
\text { flap Adhesion }\end{array}$ & $40(80 \%)$ \\
Acceptable & $\begin{array}{l}\text { Marginal flap loss } \\
\text { Salvageable }\end{array}$ & $10(20 \%)$ \\
Poor & $\begin{array}{l}\text { Major distal flap loss } \\
\text { Not salvageable Alternative }\end{array}$ \\
& mode of coverage is required & Nil \\
\hline
\end{tabular}

Results of reconstruction 


\section{Discussion:}

Groin flap was first described by Mc Gregor and Jackson in 1972 and it has been a mainstay of flap coverage to the hand defects. ${ }^{6}$ While planning the flap, the anterior superior iliac spine, the pubic tubercle and the intervening inguinal ligament are used as landmark on the skin. The origin of the SCIA is marked of the femoral artery about $2.5 \mathrm{~cm}$ below the midinguinal point. With these landmarks the flap can be raised to include the artery, though it is not essential that it should lie along the central axis of the flap. The usual width of the flap is $10 \mathrm{~cm}$ but the extremes of $06 \mathrm{~cm}$ and $19 \mathrm{~cm}$ in an adult and 14 $\mathrm{cm}$ in a child have been sued successfully. He safe maximum length is difficult to define because the lateral extent of the vascular territory is not known with certainly. Several experience would suggest that when the flap is raised beyond the anterior superior iliac spine, the part of the flap beyond this should be square, i.e. with a 1:1 length breadth ratio ${ }^{7,8}$.

When the flap is broader than average, secondary defects can usually be closed directly. Sometimes it may be necessary to flex the hip joint to reduce tension during actual closure.

The disadvantage of this flap is that it can be bulky and contain quite a lot of subcutaneous fat in some obese patients. However, it can be ideal option for soft tissue coverage in lean patients with minimal subcutaneous fat. It is often hair bearing in male patient which may not esthetically ideal when used for replacement of non-hair bearing skin.

When the flap has been inserted and well nourished in new position, its thickness of subcutaneous fat can be debulked either by surgically or suction lipectomy. The radial fore-arm flap has made available a large amount of local tissue based on radial artery to reconstruct the soft tissue defects in the hand. It offers the advantage of the one stage soft tissue reconstruction. More over surgery is confined to a single limb permitting early mobilization and rehabilitation. But the disadvantage of this flap is that one of the major artery of the fore-arm need to be sacrificed and the morbidity of the donor site is significant.

The development of free flap offers the possibility of another single stage tissue transfer. The injured limb remain free from any abnormal attachment to the body and this freedom of movement allows better control of oedema early physiotherapy and mobilization. The disadvantage of free flap surgery lies in the technical difficulties, which require microsurgical expertise and prolonged operating time. Moreover, there remains the question of safely and reliability of free flap surgery when compared to more conventional techniques 9 .

The result of this study is encouraging in terms of hand function. Adequate hand function was achieved in $88 \%$ patients which is favorably compared to the study carried out by Ikuta et al. who have showed adequate hand function in $95 \%$ of their patients.

There is no flap loss in this series. Good result was obtained in $80 \%$ patients with excellent flap adhesion. Only $20 \%$ cases, apical portion o the flap under go necrosis, which was subsequently salvaged by flap advancement.

This favorably compared to the study carried out the Mih AD who has shown terminal flap necrosis of about $15 \%$ in his series ${ }^{10}$.

\section{Conclusion:}

The problem of resurfacing of the hand in young active adults can safely be overcome by using groin flap, particularly in a developing country like Bangladesh where facilities for doing a free flap is yet to be developed.

\section{References:}

1. Gilber DA. An over view of the flaps for hand and fore-arm reconstruction. Clin Plast Surg 1981; 8: 129.

2. Chase RA. Histological review of Skin and Soft tissue coverage of the upper extremity. Hand Clin 1985; 1: 599.

3. Chase RA. The development of tissue transfer in hand surgery. J Hand Surg Am 1984; 9: 463-77.

4. Harji K, Yamada A, Torris. Recent advances in flap coverage Clin Plast Surg 1980; 7: 495.

5. Smith PJ, Foley B, Ms Gregor IA. The anatomical basis of the groin flap Plast Reconstr Surg 1981; 49: 41.

6. Mc Gregor IA and Jakson IT. The groin flap. Br J Plast Surg 1982; 25: 3-16.

7. Saeter DS, Tanner NSB. The radial fore-arm flap in the management of soft tissue injuries of the hand. Br J Plast Surg 1984; 37: 18-26.

8. Acarturk-s, Azmen-E. Composite oseteocutaneous groin flap fro the reconstruction of wrist \& forearm defects. Br J Plast Surg 1984; 37: 388-93.

9. Ikuta Y, Kimori K. Flap reconstruciton in the upper limb. Ann-Acad-Med-Singapore 1995; 24: 124-.30.

10. Mih AD. Pedicle flaps for coverage of the wrist and hand. Hand Clin 1997; 13: 217-29. 